\title{
Frekuensi Hari Hujan Menurut Bulan di Kota Balikpapan dengan Rantai Markov Waktu Diskrit
}

\author{
Muhammad Azka ${ }^{1}$ \\ ${ }^{1}$ Matematika, Matematika dan Teknologi Informasi, Institut Teknologi Kalimantan, Balikpapan. \\ Email:Muhammad.azka@itk.ac.id
}

\begin{abstract}
The problem proposed in this research is about the amount rainy day per a month at Balikpapan city and discretetime markov chain. The purpose is finding the probability of rainy day with the frequency rate of rainy at the next month if given the frequency rate of rainy at the prior month. The applied method in this research is classifying the amount of rainy day be three frequency levels, those are, high, medium, and low. If a month, the amount of rainy day is less than 11 then the frequency rate for the month is classified low, if a month, the amount of rainy day between 10 and 20, then it is classified medium and if it is more than 20, then it is classified high. The result is discrete-time markov chain represented with the transition probability matrix, and the transition diagram.
\end{abstract}

Keywords: the amount of rainy day, markov chain, discrete-time.

\begin{abstract}
Abstrak
Masalah yang dibahas pada penelitian ini berkaitan dengan jumlah hari hujan menurut bulan di kota Balikpapan dan rantai markov waktu diskrit. Adapun tujuannya adalah mengetahui peluang jumlah hari hujan dengan tingkat frekuensi hujan tertentu pada bulan berikutnya jika diketahui tingkat frekuensi hujan pada bulan sebelumnya. Metode yang dilakukan pada penelitian ini adalah dengan mengelompokkan jumlah hari hujan menjadi tiga tingkatan frekuensi, yaitu tinggi, sedang, dan rendah. Jika suatu bulan tertentu jumlah hari hujannya kurang dari 11 maka tingkatan frekuensi untuk bulan tersebut berkriteria rendah, jika jumlah hari hujannya antara 10 sampai 21 maka dikatakan berkriteria sedang dan jika lebih dari 20 maka dikriteriakan tinggi. Hasil yang didapatkan adalah bentuk model rantai markov waktu diskrit yang berupa matriks peluang transisi dan diagram transisi.
\end{abstract}

Kata Kunci: jumlah hari hujan, rantai markov, waktu diskrit.

\section{Pendahuluan}

(BPS Kota Balikpapan, 2015) memberikan laporan bahwa Kota Balikpapan beriklim tropis dengan dua musim, yaitu musim penghujan dan musim kemarau. Namun, dalam beberapa tahun terakhir cuaca di kota Balikpapan menjadi tidak pasti. Pada bulan-bulan yang seharusnya terjadi kemarau yaitu antara bulan Mei sampai Oktober yang seharusnya kemarau, pada kenyataannya terjadi musim hujan. Sebaliknya, pada bulan-bulan yang seharusnya musim penghujan yaitu antara bulan November sampai April justru jarang turun hujan.

(Kulkarni, V.G., 2011) memberikan contoh model markov waktu diskrit dengan cuaca sebagai objeknya. Pada contoh tersebut, kondisi cuaca dikelompokkan menjadi tiga kriteria, yaitu cerah, berawan, dan hujan. Jumlah hari hujan setiap bulan di kota Balikpapan ada catatannya. Data pada penelitian ini mempertimbangkan data jumlah hari hujan tahun 2014 yang diambil dari (BPS Kota Balikpapan, 2015) dan data jumlah hari hujan tahun 2015 yang diambil dari (BPS Kota Balikpapan, 2016).

Pada penelitian ini, frekuensi hari hujan pada satu bulan dikelompokkan dalam tiga kriteria. Adapun kriteria-kriteria tersebut adalah jika dalam satu bulan frekuensi hari hujannya kurang dari 11 maka frekuensi hujan dikriteriakan rendah atau jarang hujan, jika dalam satu bulan frekuensi hari hujannya antara 10 dan 21 maka frekuensi hujan dikriteriakan sedang, dan jika dalam satu bulan frekuensi hujannya lebih dari 20 maka frekuensi hujan dikriteriakan tinggi atau sering hujan. 
Inti dari model markov waktu diskrit adalah state atau keadaan di periode selanjutnya hanya tergantung dengan state pada periode sekarang. Karena pengetahuan state akan periode-periode sebelumnya dianggap bersifat pengulangan jika state pada periode sekarang sudah diketahui. Tujuan penelitian ini adalah membentuk peluang-peluang transisi satu-langkah dari state-state yang ada. Adapun ruang state pada penelitian ini ada 3, sesuai dengan banyaknya kriteria frekuensi hujan yang sudah dibuat.

\section{2. $\quad$ Metode}

(Kulkarni, V.G., 2011) Proses stokastik $\left\{X_{n}, n \geq 0\right\}$ atas ruang state $S$ disebut Rantai Markov Waktu Diskrit jika untuk setiap $i$ dan $j$ di $S$,

$$
P\left(X_{n+1}=j \mid X_{n}=i, X_{n-1}, \cdots, X_{0}\right)=P\left(X_{n+1}=j \mid X_{n}=i\right)
$$

Dan Rantai Markov Waktu Diskrit dikatakan homogen waktu jika, untuk setiap $n=0,1,{ }^{\prime \prime}$

$$
P\left(X_{n+1}=j \mid X_{n}=i\right)=P\left(X_{1}=j \mid X_{0}=i\right)
$$

Pada penelitian ini model rantai markov diasumsikan homogen waktu. $P\left(X_{n+1}=j \mid X_{n}=i\right)$ disebut peluang transisi satu-langkah dari rantai markov waktu diskrit pada waktu $n$. Untuk notasi yang lebih pendek adalah $P_{i j}=P\left(X_{n+1}=j \mid X_{n}=i\right), i, j=1,2, \cdots, N$.

\section{Hasil dan Pembahasan}

Data hari hujan yang sudah diambil dari (BPS Kota Balikpapan, 2015) dan (BPS Kota Balikpapan, 2016) diolah dengan spreadsheet. Dari situ dibuat tiga kriteria untuk frekuensi hari hujan. Sehingga, ruang state nya memiliki 3 anggota. Anggota-anggota itu disimbolkan dengan angka 0, 1, dan 2. 0 jika frekuensi hari hujan pada bulan tersebut dikategorikan jarang hujan, 1 jika frekuensi hari hujan pada bulan tersebut dikategorikan sedang, dan 2 jika frekuensi hari hujan pada bulan tersebut dikategorikan sering hujan.

Banyaknya data untuk model markov yang dibuat ada 23, walaupun data yang digunakan berasal dari 24 bulan. Data diurutkan dari januari 2014 sampai desember 2015.

Tabel 1: Data Hari Hujan Kota Balikpapan Tahun 2014-2015

\begin{tabular}{rrlclc}
\hline No. & Tahun & Bulan & $\begin{array}{c}\text { Hari Hujan } \\
\text { (Hari) }\end{array}$ & \multicolumn{1}{c}{ Kategori } & $\begin{array}{c}\text { Simbol } \\
\text { Kategori }\end{array}$ \\
\hline 1 & 2014 & Jan & 26 & sering hujan & 2 \\
2 & 2014 & Feb & 12 & frekuensi sedang & 1 \\
3 & 2014 & Mar & 17 & frekuensi sedang & 1 \\
4 & 2014 & Apr & 22 & sering hujan & 2 \\
5 & 2014 & May & 18 & frekuensi sedang & 1 \\
6 & 2014 & Jun & 21 & sering hujan & 2 \\
7 & 2014 & Jul & 14 & frekuensi sedang & 1 \\
8 & 2014 & Aug & 21 & sering hujan & 2 \\
9 & 2014 & Sep & 7 & jarang hujan & 0 \\
10 & 2014 & Oct & 7 & jarang hujan & 0 \\
11 & 2014 & Nov & 17 & frekuensi sedang & 1 \\
12 & 2014 & Dec & 22 & sering hujan & 2 \\
13 & 2015 & Jan & 26 & sering hujan & 2 \\
14 & 2015 & Feb & 17 & frekuensi sedang & 1
\end{tabular}




\begin{tabular}{cclclc}
\hline No. & Tahun & Bulan & $\begin{array}{c}\text { Hari Hujan } \\
\text { (Hari) }\end{array}$ & \multicolumn{1}{c}{ Kategori } & $\begin{array}{c}\text { Simbol } \\
\text { Kategori }\end{array}$ \\
\hline 15 & 2015 & Mar & 18 & frekuensi sedang & 1 \\
16 & 2015 & Apr & 16 & frekuensi sedang & 1 \\
17 & 2015 & May & 16 & frekuensi sedang & 1 \\
18 & 2015 & Jun & 25 & sering hujan & 2 \\
19 & 2015 & Jul & 12 & frekuensi sedang & 1 \\
20 & 2015 & Aug & 9 & jarang hujan & 0 \\
21 & 2015 & Sep & 0 & jarang hujan & 0 \\
22 & 2015 & Oct & 9 & jarang hujan & 0 \\
23 & 2015 & Nov & 18 & frekuensi sedang & 1 \\
24 & 2015 & Dec & 12 & frekuensi sedang & 1 \\
\hline
\end{tabular}

Sumber: BPS Kota Balikpapan (2015-2016).

Misalkan $X_{n}$ adalah kategori hari hujan pada bulan ke- $n$, berdasarkan data di atas maka pengelompokan kategori $X_{n}$ adalah sebagai berikut.

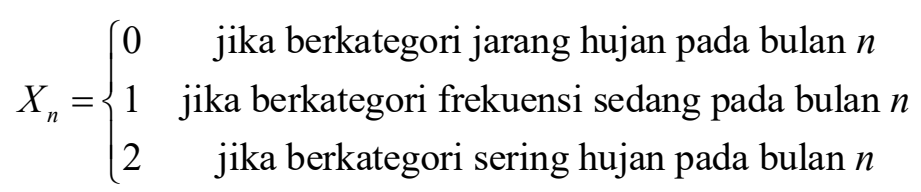

Jelas bahwa $\left\{X_{n}, n \geq 0\right\}$ adalah rantai markov waktu diskrit dengan ruang state $\{0,1,2\}$.

Dari data di atas, untuk $X_{n}=0$, yaitu state sekarang berkategori 0 , maka nilai $X_{n+1}$, yaitu state selanjutnya bisa bernilai 0,1 , atau 2 . Adapun banyaknya hubungan state 0 ke 0 ada 3, 0 ke 1 ada 2, dan 0 ke 2 ada 0 . Sehinga $p_{0,0}=\frac{3}{5}, p_{0,1}=\frac{2}{5}$, dan $p_{0,2}=0$.

Untuk $X_{n}=1$, yaitu state sekarang berkategori 1, maka nilai $X_{n+1}$, yaitu state selanjutnya bisa bernilai 0,1 , atau 2 . Adapun banyaknya hubungan state 1 ke 0 ada 1,1 ke 1 ada 5, dan 1 ke 2 ada 5. Sehingga $p_{1,0}=\frac{1}{11}, p_{1,1}=\frac{5}{11}$, dan $p_{1,2}=\frac{5}{11}$.

Untuk $X_{n}=2$, yaitu state sekarang berkategori 2, maka nilai $X_{n+1}$, yaitu state selanjutnya bisa bernilai 0,1 , atau 2 . Adapun banyaknya hubungan state 2 ke 0 ada 1,2 ke 1 ada 5, dan 2 ke 2 ada 1 . Sehingga $p_{2,0}=\frac{1}{7}, p_{2,1}=\frac{5}{7}$, dan $p_{2,2}=\frac{1}{7}$.

Matriks peluang transisi yang dihasilkan berdasarkan perhitungan di atas adalah:

Atau

$$
P=\left[\begin{array}{ccc}
\frac{3}{5} & \frac{2}{5} & 0 \\
\frac{1}{11} & \frac{5}{11} & \frac{5}{11} \\
\frac{1}{7} & \frac{5}{7} & \frac{1}{7}
\end{array}\right]
$$




$$
P=\left[\begin{array}{ccc}
0,6 & 0,4 & 0 \\
0,1 & 0,45 & 0,45 \\
0,14 & 0,72 & 0,14
\end{array}\right]
$$

Selain dalam bentuk matriks transisi sebagaimana di atas, peluang transisi satu tahap juga bisa disajikan dalam bentuk diagram transisi sebagaimana berikut ini.

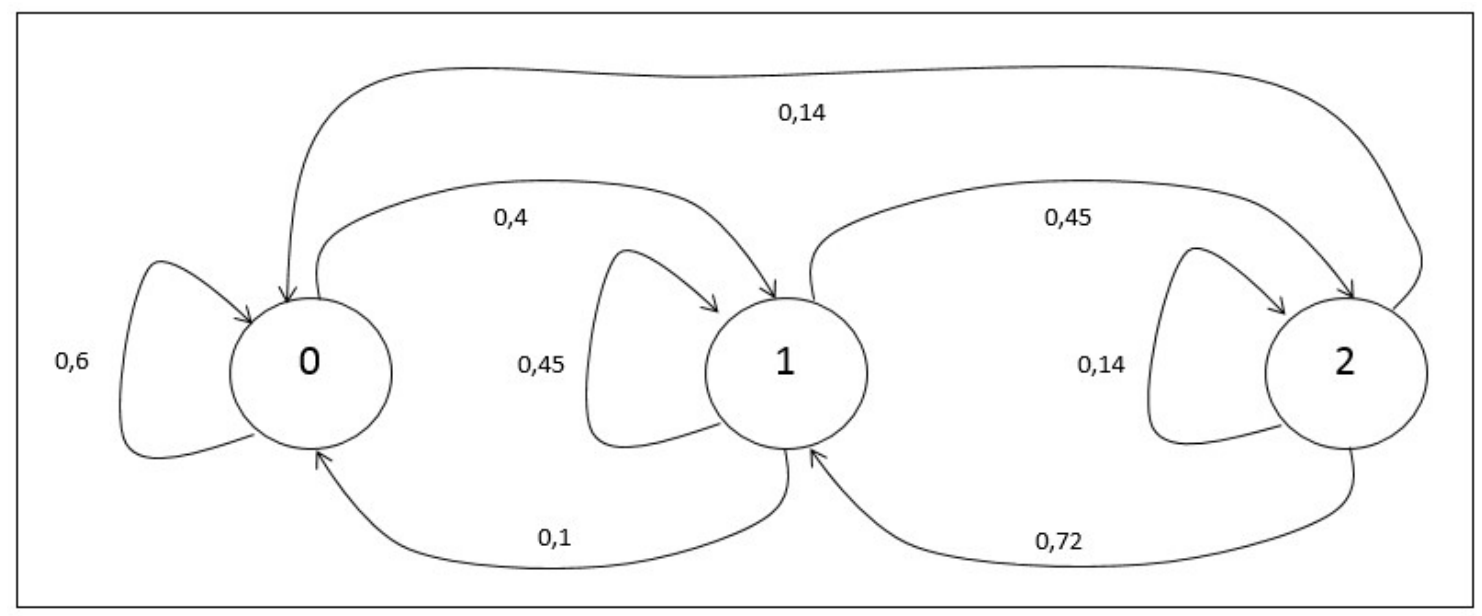

Gambar 1: Diagram Transisi dari Rantai Markov Waktu Diskrit

\section{Kesimpulan}

Berdasarkan matriks peluang transisi dan diagram transisi yang diperoleh, data bisa dimanfaatkan untuk memprediksi berapa besar peluang kategori hari hujan di bulan selanjutnya, jika diketahui kategori hari hujan untuk bulan sekarang. Misal, jika diketahui hari hujan untuk bulan ini adalah 0 atau jarang hujan, maka peluang kategori hari hujan untuk bulan depan masih 0 atau jarang hujan adalah $60 \%$. Jika diketahui hari hujan untuk bulan ini adalah 0 atau jarang hujan, maka peluang kategori hari hujan untuk bulan depan 1 atau frekuensi sedang adalah $40 \%$. Jika diketahui hari hujan untuk bulan ini adalah 0 atau jarang hujan, maka peluang kategori hari hujan untuk bulan depan 2 atau sering hujan adalah 0 .

Jika diketahui hari hujan untuk bulan ini adalah 1 atau frekuensi sedang, maka peluang kategori hari hujan untuk bulan depan 0 atau jarang hujan adalah $10 \%$. Jika diketahui hari hujan untuk bulan ini adalah 1 atau frekuensi sedang, maka peluang kategori hari hujan untuk bulan depan masih 1 atau frekuensi sedang adalah $45 \%$. Jika diketahui hari hujan untuk bulan ini adalah 1 atau frekuensi sedang, maka peluang kategori hari hujan untuk bulan depan 2 atau sering hujan adalah juga $45 \%$.

Jika diketahui hari hujan untuk bulan ini adalah 2 atau sering hujan, maka peluang kategori hari hujan untuk bulan depan 0 atau jarang hujan adalah 14\%. Jika diketahui hari hujan untuk bulan ini adalah 2 atau sering hujan, maka peluang kategori hari hujan untuk bulan depan 1 atau frekuensi sedang adalah $72 \%$. Jika diketahui hari hujan untuk bulan ini adalah 2 atau sering hujan, maka peluang kategori hari hujan untuk bulan depan masih 2 atau sering hujan adalah $14 \%$.

\section{Kesimpulan}

Jadi, berdasarkan matriks peluang transisi, hanya peluang dari kategori 0 ke 2 saja yang tidak memiliki peluang. Jika suatu state tersebut berada di 0 , maka memiliki kecenderungan state berikutnya masih tetap di 0 . Hal ini berarti, jika bulan ini jarang terjadi hujan, maka bulan berikutnya cenderung juga jarang terjadi hujan. Berbeda halnya jika state itu berada di 2 , maka state selanjutnya cenderung pindah ke state 1. Hal ini berarti, jika bulan ini sering terjadi hujan, maka bulan selanjutnya akan berkurang frekuensinya tapi juga tidak terlalu jarang hujan. 
Penelitian ini bisa dilanjutkan ke distribusi transien, yang mana bisa memprediksi state atau keadaan kategori hari hujan beberapa bulan ke depan jika diketahui state untuk bulan sekarang. Hal ini bisa dimanfaatkan misalnya untuk menghitung premi asuransi paket liburan dengan memperhitungkan faktor hujan yang bisa membatalkan acara liburan. Tentunya, jika mempertimbangkan biaya paket liburan tersebut yang direncanakan jauh-jauh hari. Hal ini berdasarkan (Kulkarni, V.G., 2011).

\section{Daftar Pustaka}

BPS Kota Balikpapan. (2015). Balikpapan Dalam Angka 2015. Bappeda Kota Balikpapan dan BPS Kota Balikpapan. Balikpapan: Badan Pusat Statistik (BPS) Kota Balikpapan. Retrieved 11 2, 2016, from https://bappeda.balikpapan.go.id/assets/filedownload/Bda_2015.pdf

BPS Kota Balikpapan. (2016, 11 2). Jumlah Hari Hujan Menurut Bulan di Kota Balikpapan, 2015. Retrieved from Badan Pusat Statistik Kota Balikpapan: https://balikpapankota.bps.go.id/linkTabelStatis/view/id/34

Kulkarni, V.G. (2011). Introduction to Modeling and Analysisis of Stochastic Systems (2 ed.). New York: Springer. 